\title{
5 Research Square

\section{Serum Levels of Cancer Antigen 125 before Hormone Replacement Therapy are not Associated with the Clinical Outcome of Frozen Embryo Transfer Cycles among Women with Adenomyosis}

\section{Ling Huang}

Sun Yat-sen University First Affiliated Hospital

Minghui Chen

Sun Yat-Sen University

\section{Zengyan Wang}

Sun Yat-Sen University

Canquan Zhou

Sun Yat-Sen University

Yubin Li ( $D$ liyubin97200@163.com )

Sun Yat-Sen University https://orcid.org/0000-0002-6847-1349

\section{Research}

Keywords: Cancer antigen 125 ,Frozen embryo transfer, Adenomyosis

Posted Date: December 10th, 2019

DOI: https://doi.org/10.21203/rs.2.18512/v1

License: (a) (i) This work is licensed under a Creative Commons Attribution 4.0 International License. Read Full License

Version of Record: A version of this preprint was published at Journal of International Medical Research on April 1st, 2021. See the published version at https://doi.org/10.1177/03000605211005878. 


\section{Abstract}

Background: Serum levels of cancer antigen 125 (CA125) are reportedly closely associated with the extent of adenomyosis. However, the association between serum CA125 levels before hormone replacement therapy (HRT) and the clinical outcome of frozen embryo transfer (FET) in patients with adenomyosis is unknown.

Methods: A total of 509 women with adenomyosis undergoing in vitro fertilization/intracytoplasmic sperm injection treatment between January 2013 and April 2019 were screened. Following the inclusion and exclusion criteria, the included patients were divided into two groups based on the serum CA125 levels ( $\leq$ or $>35 \mathrm{lU} / \mathrm{ml}$ ) before HRT. The basic characteristics and main outcomes of the two groups were compared.A receiver operating characteristic curve was used to evaluate the ability of serum CA125 levels before HRT to predict the clinical outcomes of FET. Besides, data were also separately analyzed in the GnRH agonist pretreatment subgroup.

Results: There were no significant differences in clinical outcomes between the two groups of women before HRT. A receiver operating characteristic curve demonstrated that CA125 levels were not predictive of clinical pregnancy outcomes.

Conclusions: Serum CA125 levels before HRT were not associated with the clinical outcomes of FET among women with adenomyosis. Hence, the discovery of other new markers is necessary.

\section{Background}

Adenomyosis is a benign disease of the uterus that is characterized by the presence of endometrial glands and stroma within the myometrium[1]. Although the results of studies evaluating the effects of adenomyosis on the outcome of in vitro fertilization-embryo transplantation (IVF-ET) are controversial[2], most have reported that adenomyosis has a negative impact on the clinical outcome of IVF-ET[3-5]. Thus, pretreatment with a gonadotropin-releasing hormone $(\mathrm{GnRH})$ agonist before frozen embryo transfer (FET) is applied in some women with adenomyosis [6]. Nevertheless, the effect and duration of pretreatment with a GnRH agonist before FET remain controversial $[7,8]$.

Moreover, long-term pretreatment with GnRH agonist before FET increases the duration and costs of therapy. To access the necessity of pretreatment and to predict the proper timing to start hormone replacement therapy, the discovery of a noninvasive biological marker to predict the clinical outcome of FET in women with adenomyosis is necessary.

Cancer antigen 125 (CA125) is the most widely used serum marker in screening for the presence and extent of adenomyosis [9], as Sheth and Ray reported that greater enlargement of the uterus due to severe adenomyosis was associated with a greater increase in CA125 levels [10]. Moreover, Kil et al. reported that the mean serum CA125 level of women with adenomyosis was significantly higher than that of patients with myoma [11]. However, the association between serum CA125 levels before hormone replacement therapy (HRT) and the clinical outcome of FET in patients with adenomyosis is unknown.

Therefore, the aim of this retrospective study is to evaluate the predictive value of serum CA125 levels before HRT on the pregnancy outcomes of women with adenomyosis during the FET cycles.

\section{Methods}




\section{Patient population}

The cohort of this retrospective study included 509 women with adenomyosis undergoing IVF/intracytoplasmic sperm injection (ICSI) at the Institute of Reproductive Medicine, the first affiliated Hospital of Sun Yat-sen University (Guangzhou, Guangdong, China), between January 2013 and April 2019. The inclusion criteria for the study were the following: (i) a diagnosis of adenomyosis by transvaginal color Doppler ultrasonography or magnetic resonance imaging before FET and (ii) age $\leq 39$ years at the time of commencement of IVF/ICSI. The exclusion criteria were the following: (i) the presence of hydrosalpinges, intrauterine adhesion, tumor-related disease, pelvic inflammatory diseases, and stage IV (severe) endometriosis, (ii) endometrial thickness of $<7 \mathrm{~mm}$ on the day of transformation before FET, (iii) prior preimplantation genetic testing, and (iv) the partner of the patient underwent testicular sperm extraction because of non-obstructive azoospermia.

Finally, 84 patients who underwent a total of 118 cycles of FET were included in the final analysis. The included patients were divided into two groups based on the traditional serum CA125 level cut-off value of $35 \mathrm{U} / \mathrm{ml}$ before endometrial preparation using HRT: group A with normal CA125 levels ( $\leq 35 \mathrm{U} / \mathrm{ml}, \mathrm{n}=74$ cycles) and group B with abnormal CA125 levels (>35 U/ml, $\mathrm{n}=44$ cycles).

\section{Cryopreservation and thawing}

After ovarian stimulation and oocyte retrieval, embryos were produced by IVF or ICSI. On day 3 or 5 after oocyte retrieval, the embryos were graded using a standardized scoring system. Embryos that met the eligibility criteria were regarded as viable and subsequently cryopreserved using the vitrification freezing method. The vitrification and thawing procedures were previously described by Kuwayama et al. [12]. Briefly, embryo vitrification was performed using a Cryotop ${ }^{\circledR}$ Vitrification system (Kitazato Corporation, Tokyo, Japan) with dimethyl sulfoxide, ethylene glycol, and sucrose as cryoprotectants. The embryos were thawed in decreasing levels of sucrose solution $(1,0.5$, and $0 \mathrm{M})$.

\section{FET procedure}

As a pretreatment, the GnRH agonist was administrated during the early follicular phase of the menstrual cycle. The day before starting the HRT protocol, serum CA125 levels were measured. Oral estradiol valerate was administered at $4 \mathrm{mg} /$ day for 14 days. If the thickness of the endometrium was $\geq 7 \mathrm{~mm}$, progesterone was administrated. Day 3 (D3) embryos were transferred on D4 of progesterone administration, and D5 or D6 blastocysts were transferred on D6 of progesterone administration.

If the endometrium had not reached a thickness of $7 \mathrm{~mm}$ by D15, the dose of estradiol valerate was increased and continued for an additional $3-5$ days. If the endometrial thickness was not $7 \mathrm{~mm}$ by D20, the cycle was usually cancelled.

The same doses of estrogen and progesterone were administered until a serum beta human chorionic gonadotropin assay was conducted at D14 after FET. If the assay result was positive, HRT was continued until week 10 of the pregnancy.

\section{Outcome measures}

The implantation rate was defined as the number of gestational sacs observed by ultrasonography divided by the number of transferred embryos. Clinical pregnancy was defined as the presence of an active fetal heart as detected by ultrasonography at 5 weeks after FET. The miscarriage rate was defined as the number of clinical pregnancies 
lost before 28 weeks of pregnancy divided by the total number of clinical pregnancies. Ongoing pregnancy was defined as a viable intrauterine pregnancy of at least 12 weeks, as confirmed by ultrasonography.

\section{Statistical analysis}

The Kolmogorov-Smirnov test was used to determine if the continuous variables were normally distributed. The unpaired Student's t-test was used to compare normally distributed data, and the Mann-Whitney U test was used to compare skewed data. Categorical variables were analyzed using the chi-square test or Fisher's exact test, where appropriate. Binary logistic regression analysis was performed to detect the association between serum CA125 levels before HRT and the clinical outcomes of FET when the baseline demographic and clinical variables of two groups of patients were significantly different. A receiver operating characteristic (ROC) curve was used to evaluate the ability of serum CA125 levels before HRT to predict the clinical outcomes of FET. Statistical analysis was performed using IBM SPSS Statistics for Windows version 23.0 (IBM Corporation, Armonk, NY, USA). A probability (p) value of $\leq 0.05$ was considered statistically significant.

\section{Results}

A total of 84 patients who underwent 118 FET cycles were included for analysis. Adenomyosis was diagnosed by transvaginal color Doppler ultrasonography or magnetic resonance imaging. The serum CA125 levels before 44 cycles of HRT were greater than $35 \mathrm{U} / \mathrm{ml}$ and less than $35 \mathrm{U} / \mathrm{ml}$ before 74 cycles.

The baseline demographic and clinical variables of the two groups of patients are presented in Table 1. There was no significant difference in age at freezing, age at thawing, body mass index, duration of infertility, cause of infertility, fertilization method, previous number of thawing cycles, developmental stage of the transferred embryos, number of transferred embryos, distribution of $\mathrm{GnRH}$ agonist pretreatment, and basal uterine volume before $\mathrm{GnRH}$ agonist administration between the groups. Moreover, there was no significant difference in endometrium thickness, E2 levels, and progesterone levels between the two groups on the day of progesterone administration. However, the mean serum CA125 level before GnRH agonist administration was significantly higher in the CA125 > $35 \mathrm{U} / \mathrm{ml}$ group than in the CA125 $\leq 35 \mathrm{U} / \mathrm{ml}$ group. Further, the antral follicle count was significantly lower in the CA125 $\leq 35 \mathrm{U} / \mathrm{ml}$ group than in the CA125 > $35 \mathrm{U} / \mathrm{ml}$ group. 
Table 1

Baseline demographic and clinical variables of two groups of patients

\begin{tabular}{|c|c|c|c|}
\hline & $\begin{array}{l}\mathrm{CA} 125 \leq 35 \mathrm{U} / \mathrm{ml} \\
(\mathrm{N}=74)\end{array}$ & $\begin{array}{l}\mathrm{CA} 125 \llbracket 35 \mathrm{U} / \mathrm{ml} \\
(\mathrm{N}=44)\end{array}$ & P Value \\
\hline Age at freezing(years) & $32.88 \pm 3.72$ & $32.00 \pm 3.97$ & 0.24 \\
\hline Age at thawing(years) & $33.59 \pm 3.62$ & $32.82 \pm 4.04$ & 0.33 \\
\hline BMI (kg/m2) & $21.43 \pm 2.80$ & $21.52 \pm 2.46$ & 0.87 \\
\hline Duration of infertility (years) & $3.97 \pm 2.83$ & $3.76 \pm 3.35$ & 0.43 \\
\hline $\begin{array}{l}\text { Cause of infertility, } \mathrm{n}(\%) \\
\text { Male } \\
\text { Tube and pelvic cavity } \\
\text { Mixed }\end{array}$ & $\begin{array}{l}11(14.86 \%) \\
43(58.11 \%) \\
20(27.03 \%)\end{array}$ & $\begin{array}{l}13(29.55 \%) \\
22(50 \%) \\
9(20.45 \%)\end{array}$ & 0.37 \\
\hline Antral follicle count & $7.91 \pm 4.03$ & $9.39 \pm 4.12$ & 0.03 \\
\hline Previous thawing cycle number & $0.59 \pm 0.83$ & $0.64 \pm 0.78$ & 0.66 \\
\hline $\begin{array}{l}\text { Fertilization method n(\%) } \\
\text { IVF } \\
\text { ICSI }\end{array}$ & $\begin{array}{l}56(75.68 \%) \\
18(24.32 \%)\end{array}$ & $\begin{array}{l}37(84.09 \%) \\
7(15.91 \%)\end{array}$ & 1.00 \\
\hline Basal serum CA-125 (U/ml) & $98.62 \pm 96.32$ & $145.63 \pm 119.71$ & 0.004 \\
\hline Basal Uterine volume(cm3) & $123.16 \pm 81.50$ & $139.21 \pm 104.52$ & 0.47 \\
\hline $\begin{array}{l}\text { GnRHa pretreatment } \mathrm{n}(\%) \\
\text { Yes } \\
\text { No }\end{array}$ & $\begin{array}{l}62(83.78 \%) \\
12(16.22 \%)\end{array}$ & $\begin{array}{l}37(84.09 \%) \\
7(15.91 \%)\end{array}$ & 1.00 \\
\hline Number of transferred embryos & $1.69 \pm 0.60$ & $1.89 \pm 0.62$ & 0.09 \\
\hline $\begin{array}{l}\text { Stage of transferred embryos } \\
\text { Blastocyst } \\
\text { Cleavage }\end{array}$ & $\begin{array}{l}33(44.59 \%) \\
41(55.41 \%)\end{array}$ & $\begin{array}{l}12(27.27 \%) \\
32(72.73 \%)\end{array}$ & 1.00 \\
\hline Endometrium thickness on progesterone day (mm) & $8.93 \pm 1.35$ & $9.42 \pm 1.54$ & 0.06 \\
\hline E2 level on progesterone administration day $(\mathrm{pg} / \mathrm{ml})$ & $199.18 \pm 229.82$ & $215.50 \pm 263.90$ & 0.67 \\
\hline p Level on progesterone administration day (ng/ml) & $0.21 \pm 0.09$ & $0.20 \pm 0.07$ & 0.88 \\
\hline \multicolumn{4}{|c|}{$\begin{array}{l}\mathrm{N}=\text { the total number of frozen embryo transfer cycles, } \mathrm{n}=\text { the number of subjects with data. Values are mean } \pm \\
\text { standard deviation or } \mathrm{n}(\%) \\
\mathrm{CA1} 25 \text {, cancer antigen } 125 ; \mathrm{BMI}, \text { body mass index; IVF,in vitro fertilization; ICSI,intracytoplasmic sperm injection } \\
; \text {;GRRHa,gonadotropin-releasing hormone agonist;E2,estradiol;p,progesterone. }\end{array}$} \\
\hline
\end{tabular}

The clinical outcomes of the two groups are shown in Table 2. There were no significant differences in implantation rates between the $\mathrm{CA} 125 \leq 35 \mathrm{U} / \mathrm{ml}$ and $\mathrm{CA} 125>35 \mathrm{U} / \mathrm{ml}$ groups $(27.20 \%$ vs. $22.89 \%$, respectively, $\mathrm{p}$ $=1.00$ ). However, the clinical pregnancy rate was slightly higher in the CA125 $\leq 35 \mathrm{U} / \mathrm{ml}$ group before HRT, but the difference was not significant ( $37.84 \%$ vs. $31.82 \%$, respectively, $p=1.00)$. Moreover, although not significant, the ongoing pregnancy rate was slightly higher in the CA125 $\leq 35 \mathrm{U} / \mathrm{ml}$ group $(32.43 \%$ vs. $27.27 \%$, respectively, $\mathrm{p}=$ $1.00)$, and the miscarriage rate was slightly lower $(15.79 \%$ vs. $35.71 \%$, respectively, $p=1.00)$. 
Table 2

Clinical outcome of two groups of patients

\begin{tabular}{|c|c|c|c|}
\hline & $\begin{array}{l}\mathrm{CA} 125 \leq 35 \mathrm{U} / \mathrm{ml} \\
(\mathrm{N}=74)\end{array}$ & $\begin{array}{l}\text { CA125『35 U/ml } \\
(\mathrm{N}=44)\end{array}$ & $P$ value \\
\hline Implantation rate $\mathrm{n}(\%)$ & $34(27.20 \%)$ & $19(22.89 \%)$ & 1.00 \\
\hline Clinical pregnancy rate $\mathrm{n}(\%)$ & & $14(31.82 \%)$ & 1.00 \\
\hline Ongoing pregnancy rate $n(\%)$ & $24(32.43 \%)$ & $12(27.27 \%)$ & 1.00 \\
\hline Miscarriage rate n(\%) & $6(15.79 \%)$ & $5(35.71 \%)$ & 1.00 \\
\hline
\end{tabular}

Given that pretreatment with the GnRH agonist is an important factor affecting the pregnancy outcomes of FET, data were separately analyzed in the $\mathrm{GnRH}$ agonist pretreatment subgroup. The results of the subgroup analysis for the patients with $\mathrm{GnRH}$ agonist pretreatment before HRT are shown in Table 3. Notably, there were no significant differences in the clinical outcomes of the two subgroups.

Table 3

Subgroup analysis of two groups of patients with GnRHa pretreatment before HRT

\begin{tabular}{|c|c|c|c|}
\hline & $\begin{array}{l}\mathrm{CA} 125 \leq 35 \mathrm{U} / \mathrm{ml} \\
(\mathrm{N}=62)\end{array}$ & $\begin{array}{l}\text { CA125『35 } \mathrm{U} / \mathrm{ml} \\
(\mathrm{N}=37)\end{array}$ & $P$ value \\
\hline The dosage of GnRHa pretreatment $(\mathrm{mg})$ & $6.16 \pm 3.48$ & $5.56 \pm 2.68$ & 0.58 \\
\hline Implantation rate $\mathrm{n}(\%)$ & $27(26.21 \%)$ & $16(23.19 \%)$ & 1.00 \\
\hline Clinical pregnancy rate $\mathrm{n}(\%)$ & $22(35.48 \%)$ & $12(32.43 \%)$ & 1.00 \\
\hline Ongoing pregnancy rate $n(\%)$ & $18(29.03 \%)$ & $10(27.03 \%)$ & 1.00 \\
\hline Miscarriage rate $\mathrm{n}(\%)$ & $6(27.27 \%)$ & 4(33.33\%) & 1.00 \\
\hline
\end{tabular}

After adjusting for the antral follicle count during the freeze cycles and basal serum CA125 levels, the two groups still had similar chances of clinical pregnancy (adjusted odds ratio $[\mathrm{OR}]=1.58 ; 95 \%$ confidence interval $[\mathrm{Cl}]=0.68-$ 3.68), ongoing pregnancy (adjusted $\mathrm{OR}=1.53 ; 95 \% \mathrm{Cl}=0.64-3.68$ ), and miscarriage (adjusted $\mathrm{OR}=1.07 ; 95 \% \mathrm{Cl}=$ $0.10-11.08$ ). The GnRH agonist pretreatment subgroups also had similar chances of clinical pregnancy (adjusted $\mathrm{OR}=1.30 ; 95 \% \mathrm{Cl}=0.53-3.22$ ), ongoing pregnancy (adjusted $\mathrm{OR}=1.25 ; 95 \% \mathrm{Cl}=0.48-3.23$ ), and miscarriage (adjusted $\mathrm{OR}=0.73 ; 95 \% \mathrm{Cl}=0.15-3.46$ ). The results of the binary logistic regression analyses are shown in Tables 4 and 5 . 
Table 4

Logistics regression analysis for pregnancy outcomes of two groups of patients

\begin{tabular}{|c|c|c|c|c|c|c|}
\hline $\begin{array}{l}\text { pregnancy } \\
\text { outcomes }\end{array}$ & $\begin{array}{l}\mathrm{CA} 125 \leq \\
35 \mathrm{U} / \mathrm{ml} \\
\mathrm{N}=74(\mathrm{n} \%)\end{array}$ & $\begin{array}{l}\text { CA125囚35 U/ml } \\
\mathrm{N}=44(\mathrm{n} \%) \\
\text { (Reference) }\end{array}$ & $\begin{array}{l}\text { Crude odds } \\
\text { ratio( } 95 \% \text { confidence } \\
\text { interval) }\end{array}$ & $\begin{array}{l}P \\
\text { value }\end{array}$ & $\begin{array}{l}\text { Adjusted odds } \\
\text { ratio( } 95 \% \text { confidence } \\
\text { interval) }\end{array}$ & $\begin{array}{l}\mathrm{P} \\
\text { value }\end{array}$ \\
\hline $\begin{array}{l}\text { Clinical } \\
\text { pregnancy }\end{array}$ & $28(37.84 \%)$ & 14(31.82\%) & $1.30(0.59-2.87)$ & 0.51 & $1.58(0.68-3.68)$ & 0.29 \\
\hline $\begin{array}{l}\text { Ongoing } \\
\text { pregnancy }\end{array}$ & $24(32.43 \%)$ & $12(27.27 \%)$ & $1.28(0.56-2.91)$ & 0.56 & $1.53(0.64-3.68)$ & 0.34 \\
\hline Miscarriage & 6(15.79\%) & $5(35.71 \%)$ & $0.6(0.20-2.40)$ & 0.56 & $0.7(0.19-2.64)$ & 0.62 \\
\hline
\end{tabular}

Table 5

Logistics regression analysis for pregnancy outcomes of two groups of patients with GnRH agonist pretreatment

\begin{tabular}{|c|c|c|c|c|c|c|}
\hline $\begin{array}{l}\text { pregnancy } \\
\text { outcomes }\end{array}$ & $\begin{array}{l}\mathrm{CA} 125 \leq \\
35 \mathrm{U} / \mathrm{ml} \\
\mathrm{N}=62(\mathrm{n} \%)\end{array}$ & $\begin{array}{l}\text { CA125囚35 U/ml } \\
\mathrm{N}=37(\mathrm{n} \%) \\
\text { (Reference) }\end{array}$ & $\begin{array}{l}\text { Crude odds } \\
\text { ratio( } 95 \% \text { confidence } \\
\text { interval) }\end{array}$ & $\begin{array}{l}\mathrm{P} \\
\text { value }\end{array}$ & $\begin{array}{l}\text { Adjusted odds } \\
\text { ratio( } 95 \% \text { confidence } \\
\text { interval) }\end{array}$ & $\begin{array}{l}P \\
\text { value }\end{array}$ \\
\hline $\begin{array}{l}\text { Clinical } \\
\text { pregnancy }\end{array}$ & $22(35.48 \%)$ & $12(32.43 \%)$ & $1.15(0.48-2.72)$ & 0.51 & $1.30(0.53-3.22)$ & 0.57 \\
\hline $\begin{array}{l}\text { Ongoing } \\
\text { pregnancy }\end{array}$ & $18(29.03 \%)$ & $10(27.03 \%)$ & $1.11(0.45-2.74)$ & 0.83 & $1.25(0.48-3.23)$ & 0.65 \\
\hline Miscarriage & $6(27.27 \%)$ & $4(33.33 \%)$ & $0.75(0.16-3.44)$ & 0.71 & $0.73(0.15-3.46)$ & 0.69 \\
\hline \multicolumn{7}{|c|}{$\begin{array}{l}\text { Analysis were adjusted for antral follicle count and basal serum CA- } 125 \text {. } \\
N=\text { the total number of frozen embryo transfer cycles, } n=\text { the number of subjects with data. } \\
\text { GnRHa, gonadotropin-releasing hormone agonist; CA125,cancer antigen } 125 \text {. }\end{array}$} \\
\hline
\end{tabular}

As shown in Fig. 1, the area under the ROC curve was $0.463(p=0.511)$, demonstrating that CA125 levels had no predictive value for the outcome of clinical pregnancy.

\section{Discussion}

To the best of our knowledge, this study is the first to qualify the impact of adenomyosis on the pregnancy outcome of FET based on serum CA125 as a biological marker. The results of the present study demonstrated that there was no prognostic significance of serum CA125 before HRT on the outcome of FET.

Previous studies demonstrated that the extent of adenomyosis was associated with reproductive outcomes [13] and more severe adenomyosis was associated with a greater increase in serum CA125 levels [10]. However, the presence of adenomyosis may associate with numerous conditions thought to impair embryo implantation.It was reported that the junctional zone of myometrial activity was altered because of adenomyosis. Furthermore, researchrevealed that an abnormal contraction activity of the junctional zone in patients with adenomyosiswas associated with lower implantation and pregnancy rates of IVF-ET [14]. Moreover, vascularization of the 
endometrial stroma was found to be unexpectedly increased in the case of adenomyosis, which negatively affects embryo implantation [15]. Further, changes in the expression profile of cytokines and growth factors in the endometrium have been related to adenomyosis-associated infertility [16]. Therefore, a mere increase in serum CA125 levels is not an appropriate measure of the complicated influence of adenomyosison the clinical outcome of FET. Furthermore, serum CA125 is less reliable as a marker in premenopausal women because of increases in response to various conditions, such as endometriosis, adenomyosis, tumor formation, and even menstruation [17]. And an irrelevant increase in serum CA125 levels can result in misdiagnosis.

The results of the subgroup analysis showed that the serum CA125 levels before HRT were not associated with the clinical outcome of FET in patients pretreated with the GnRH agonist. A study by Xie et al. reported that the serum CA125 levels were significantly reduced after long-term treatment with the GnRH agonist in patients with adenomyosis [18], and Niu et al. reported that long-term pituitary downregulation before FET could improve pregnancy outcomes in these women [19]. Lower serum CA125 levels could be associated with shrinking of the uterus and milder pelvic adhesions [10,20]. However, the reasons for the improved pregnancy outcomes of these patients are complicated and not well understood [21, 22]. Thus, a decrease in serum CA125 levels before HRT is not predictive of the clinical outcome of FET in patients with adenomyosis.

There were some limitations to this study, especially the retrospective nature of the study and the relatively small sample, which could cause bias. Hence, further prospective studies with larger cohorts are required to verify the results of this study.

In conclusion, the results of our study suggested that the serum CA125 levels before HRT were not related to the rates of implantation, clinical pregnancy, ongoing pregnancy, or miscarriage of FET in women with adenomyosis. Hence, the sole detection of serum CA125 levels before HRT is invalid, resulting in a waste of money and increased anxiety of the patient. The combined detection of other biological markers or the discovery of other new markers will be necessary to increase the predictive accuracy in the future.

\section{List Of Abbreviations}

CA125:Cancer antigen 125

HRT:Hormone replacement therapy

FET:Frozen embryo transfer

IVF-ET: In vitro fertilization-embryo transplantation

GnRH: Gonadotropin-releasing hormone

ICSI:Intracytoplasmic sperm injection

D3囚Day 3

ROC $₫$ Receiver operating characteristic

OR $₫$ Odds ratio

Cl: Confidence interval 


\section{Declarations}

\section{Ethics approval and consent to participate}

The study was approved by the Institutional Review Board of the First Affiliated Hospital of Sun Yat-sen University.Since this is a retrospective investigation, patients were not asked to participate in this study.

\section{Consent for publication}

Not applicable.

\section{Availability of data and materials}

The data sets used and/or analyzed during the current study are available from the database of Center for Reproductive Medicine in the First Affiliated Hospital of Sun Yat-sen University on reasonable request.

\section{Competing interests}

The authors declare that they have no competing interests.

\section{Funding}

This work was supported by the Guangdong Provincial Key Laboratory of Reproductive Medicine (2012A061400003) and Guangzhou Science and Technology Project: Development and Application of The Reagents for Preimplantation Diagnosis and Screening by Next Generation Sequencing (201704020217).

\section{Author Contributions}

Ling Huang, Canquan Zhou and Yubin Liconceived and designed the study. Ling Huang, Minghui Chen and Zengyan Wangperformed the evaluation and collected data. Ling Huang, Minghui Chen and Yubin Lianalyzed the data.Minghui Chen and Zengyan Wangcontributed evaluation instruments and final approval. Ling Huang, Canquan Zhou and Yubin Liwrote the paper.

\section{Acknowledgements}

None.

\section{References}

1. Movilla P, Morris S, Isaacson K: A Systematic Review of Tissue Sampling Techniques for the Diagnosis of Adenomyosis. J Minim Invasive Gynecol 2019.

2. Younes G, Tulandi T: Effects of adenomyosis on in vitro fertilization treatment outcomes: a meta-analysis. Fertil Steril 2017, 108:483-490.e483.

3. Salim R, Riris S, Saab W, Abramov B, Khadum I, Serhal P: Adenomyosis reduces pregnancy rates in infertile women undergoing IVF. Reprod Biomed Online 2012, 25:273-277. 
4. Sharma S, Bathwal S, Agarwal N, Chattopadhyay R, Saha I, Chakravarty B: Does presence of adenomyosis affect reproductive outcome in IVF cycles? A retrospective analysis of 973 patients. Reprod Biomed Online 2019, 38:1321.

5. Stanekova V, Woodman RJ, Tremellen K: The rate of euploid miscarriage is increased in the setting of adenomyosis. Hum Reprod Open 2018, 2018:hoy011

6. Park CW, Choi MH, Yang KM, Song IO: Pregnancy rate in women with adenomyosis undergoing fresh or frozen embryo transfer cycles following gonadotropin-releasing hormone agonist treatment. Clin Exp Reprod Med 2016, 43:169-173.

7. Huang FJ, Kung FT, Chang SY, Hsu TY: Effects of short-course buserelin therapy on adenomyosis. A report of two cases. J Reprod Med 1999, 44:741-744.

8. Soritsa D, Saare M, Laisk-Podar T, Peters M, Soritsa A, Matt K, Karro H, Salumets A: Pregnancy rate in endometriosis patients according to the severity of the disease after using a combined approach of laparoscopy, GnRH agonist treatment and in vitro fertilization. Gynecol Obstet Invest 2015, 79:34-39

9. Kil K, Chung JE, Pak HJ, Jeung IC, Kim JH, Jo HH, Kim MR: Usefulness of CA125 in the differential diagnosis of uterine adenomyosis and myoma. Eur J Obstet Gynecol Reprod Biol 2015, 185:131-135.

10. Sheth SS, Ray SS: Severe adenomyosis and CA125. J Obstet Gynaecol 2014, 34:79-81.

11. Kil K, Chung JE, Pak HJ, Jeung IC, Kim JH, Jo HH, Kim MR: Usefulness of CA125 in the differential diagnosis of uterine adenomyosis and myoma. Eur J Obstet Gynecol Reprod Biol 2015, 185:131-135.

12. Kuwayama M: Highly efficient vitrification for cryopreservation of human oocytes and embryos: the Cryotop method. Theriogenology 2007, 67:73-80.

13. Dueholm M: Uterine adenomyosis and infertility, review of reproductive outcome after in vitro fertilization and surgery. Acta Obstet Gynecol Scand 2017, 96:715-726.

14. Exacoustos C, Luciano D, Corbett B, De Felice G, Di Feliciantonio M, Luciano A, Zupi E: The uterine junctional zone: a 3-dimensional ultrasound study of patients with endometriosis. Am J Obstet Gynecol 2013, 209:248.e241247.

15. Mavrelos D, Holland TK, O'Donovan O, Khalil M, Ploumpidis G, Jurkovic D, Khalaf Y: The impact of adenomyosis on the outcome of IVF-embryo transfer. Reprod Biomed Online 2017, 35:549-554.

16. Harada T, Khine YM, Kaponis A, Nikellis T, Decavalas G, Taniguchi F: The Impact of Adenomyosis on Women's Fertility. Obstet Gynecol Surv 2016, 71:557-568.

17. Malkasian GD, Knapp RC, Lavin PT, Zurawski VR, Podratz KC, Stanhope CR, Mortel R, Berek JS, Bast RC, Ritts RE: Preoperative evaluation of serum CA 125 levels in premenopausal and postmenopausal patients with pelvic masses: discrimination of benign from malignant disease. Am J Obstet Gynecol 1988, 159:341-346.

18. Xie M, Yu H, Zhang X, Wang W, Ren Y: Elasticity of adenomyosis is increased after GnRHa therapy and is associated with spontaneous pregnancy in infertile patents. J Gynecol Obstet Hum Reprod 2019.

Page $10 / 12$ 
19. Niu Z, Chen Q, Sun Y, Feng Y: Long-term pituitary downregulation before frozen embryo transfer could improve pregnancy outcomes in women with adenomyosis. Gynecol Endocrinol 2013, 29:1026-1030.

20. Lee Y, Lee Y, Lee S, Jung S, Chon S: Correlation of Preoperative Biomarkers with Severity of Adhesion in Endometriosis. J Gynecol Obstet Hum Reprod 2019:101637.

21. Khan KN, Kitajima M, Hiraki K, Fujishita A, Nakashima M, Ishimaru T, Masuzaki H: Cell proliferation effect of $\mathrm{GnRH}$ agonist on pathological lesions of women with endometriosis, adenomyosis and uterine myoma. Hum Reprod 2010, 25:2878-2890.

22. Morimoto C, Osuga Y, Yano T, Takemura Y, Harada M, Hirata T, Hirota Y, Yoshino O, Koga K, Kugu K, Taketani Y: $\mathrm{GnRH}$ II as a possible cytostatic regulator in the development of endometriosis. Hum Reprod 2005, 20:3212-3218.

\section{Figures}

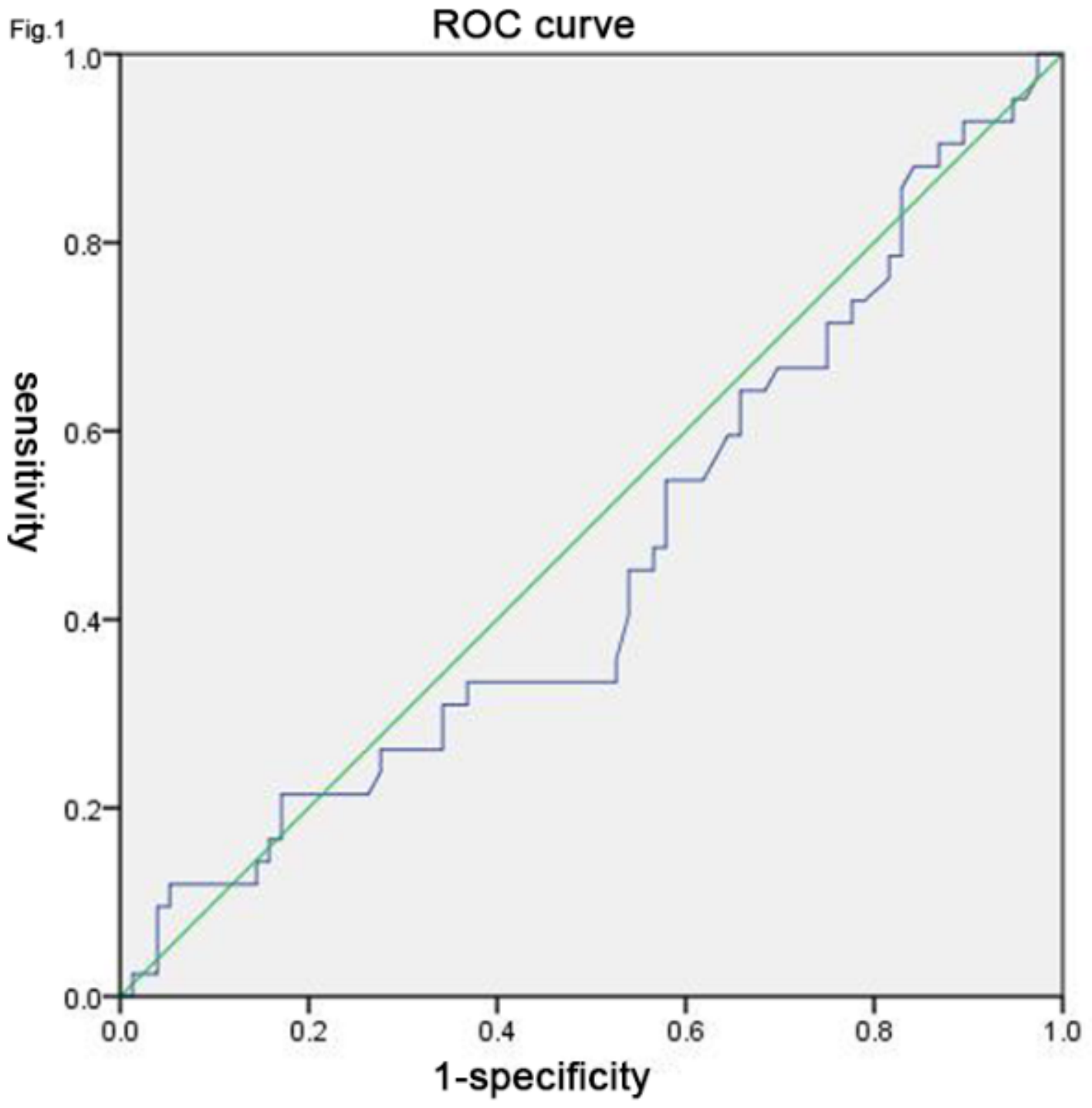

Figure 1 
Receiver operating characteristics(ROC) curve for Serum Levels of cancer antigen 125(CA125) before hormone replacement therapy (HRT) as predictor of clinical pregnancy among patients with adenomyosis in the frozen embryo transfer cycles. 